\title{
O DANO EXISTENCIAL COMO UMA NOVA MODALIDADE DE DANO NÃO PATRIMONIAL: A NECESSIDADE DA AMPLIAÇÃO DO PRINCÍPIO DA FUNÇÃO SOCIAL DA RESPONSABILIDADE CIVIL E A BUSCA DA REPARAÇÃO INTEGRAL DO DANO À PESSOA
}

\author{
THE EXISTENTIAL DAMAGE AS A NEW MODALITY OF A NON - PATRIMONIAL DAMAGE: THE \\ NECESSITY OF WIDENING THE PRINCIPLE OF THE SOCIAL FUNCTION OF CIVIL LAW AND \\ THE QUEST FOR AN INTEGRAL COMPENSATION TO A PERSONAL DAMAGE
}

Elaine Buarque $^{1}$

RESUMO: Visa-se, com este artigo, fornecer uma contribuição acadêmica, no sentido de mostrar um novo olhar sobre o dano à pessoa, que pode advir de uma lesão existencial, e, apesar de se iniciar no centro do sentir humano, prolonga-se em seu existir (dirigido a si próprio) e nas suas relações coexistenciais (dirigida aos demais membros da sociedade). A partir do recorte epistemológico, derivado do movimento de Constitucionalização do Direito Civil e da repersonalização das relações, foi desenvolvido o estudo de um dano que, contempla não apenas à pessoa, mas, de forma ampla, os direitos democraticamente consolidados pela Constituição Federal, representados pelos princípios da sociabilidade, solidariedade e da dignidade da pessoa humana. Proteger o indivíduo é, sobretudo, permitir que cada um se desenvolva em sociedade, segundo suas perspectivas e potencialidades, por isso, a busca pela reparação integral do dano causado à pessoa humana e a proteção desta, contra qualquer tipo de dano, são objetivos precípuos do ordenamento jurídico, albergados sob a égide do

\begin{abstract}
Our aim with this paper is to provide an academic contribution, in order to show a new view on the damage to the person, which might arise from an existential damage. And, although it starts at the center of the human feeling, it extends to one's existence (directed to himself) and in his coexistential relations (towards to the other members of society). From the outline of epistemology, derived from the Constitutionalisation of Civil Law and from the repersonalization of relations, it was developed the study of an injury that contemplates not only the person, but, broadly, the rights democratically consolidated by the Federal Constitution and represented by the principles of sociability, solidarity and the dignity of the human person. Protecting the individual is, above all, to enable each one to develop in society, according to their perspectives and potentialities, therefore, the quest for full reparation of the damage caused to the human person and the protection of this person, against any kind of harm, are overriding goals for the legal order, sheltered under the aegis of the
\end{abstract}

\footnotetext{
${ }^{1}$ Doutora em Direito Civil pela Universidade Federal de Pernambuco, bolsista Capes pelo Programa de Doutorado Sanduíche no Exterior - Università di Camerino (Itália). Mestre em Direito Civil pela Universidade Federal de Pernambuco, advogada, parecerista, e professora universitária nas disciplinas de Direito Civil e Direito do Consumidor da Faculdade de Olinda (FOCCA) e Faculdade Salesiana do Nordeste (FASNE). ORCID n. 0000-0001-6328-2162.
} 


\section{Revista IBERC}

v. 2, n. 2, p. 01-22, mai.-ago./2019

www.responsabilidadecivil.org

princípio da dignidade da pessoa humana, aptos a justificarem a ampliação das modalidades de danos já existentes, abrangendo a pessoa no seu existir e coexistir em suas mais diversas formas de interação social. A problemática do presente artigo é apresentada em torno da análise quanto à viabilidade e à concretude da aplicabilidade do conceito jurídico do dano existencial ao ordenamento pátrio. Partindo-se da premissa que o dano existencial é externo, que se irradia e fere um interesse individual, sendo capaz de ocasionar a alteração permanente nas atividades hedonistas e na vida de relações da vítima (ou seja, desta em relação às demais pessoas em sociedade e dessas pessoas, em relação àquele que sofreu o dano). Chega-se à conclusão de que as consequências do dano existencial vão além das ocasionadas pelo dano moral. Logo, o dano existencial não atinge tão somente aquela que foi vítima do mesmo, mas, de maneira direta, pessoas que estão em correlação existencial com a pessoa lesada. Não se trata de perda de uma chance ou de mero dano a um projeto de vida e sim da extinção, cerceamento ou impedimento da realização de uma atividade, lazer ou relacionamento, antes existentes. $O$ dano existencial, uma vez ocasionado, por conseguinte, tem o condão de transformar a realidade situacional - temporal - espacial da pessoa que o sofreu, de forma a tolher-lhe o que há de mais precioso, a sua motivação existencial. A maior ou talvez a mais importante característica dessa nova modalidade de dano, neste artigo proposto, sob a denominação de dano existencial, é a ampliação da função social do instituto da responsabilidade civil.

Palavras-chave: Direito Civil Constitucional. Dano existencial. Princípio da Função Social no Direito Civil. principle of the dignity of the human person, capable of justifying the widening of already existing categories of damages, including the person in his existence and coexistence in their most diverse forms of social interaction. The issue of the following work is to show around the analysis as to the viability and the concreteness of the applicability of the legal concept of existential damage to Brazilian law. Starting from the premise that the existential damage is external, that it radiates and hurts an individual interest, being able to cause the lifelong alteration, in the hedonistic activities and in the life of relations of the victim (that means, from this one person in relation to the other people in society and from these people in relation to that person who suffered the damage). It is concluded that the consequences of existential damage go beyond those caused by non-material damages. Therefore, the existential damage does not merely affect the one who has been a victim of it, but, directly, people who are in existential correlation with the injured person. It is not a matter of loss of a chance or mere damage to a life project, but on the contrary of the extinction, restriction or impediment of performing an activity, leisure, or relationship existing before The existential damage, once occasioned, consequently, has the power to transform the situational - temporal - spatial reality of the person who suffered it, in way that prevents what is most precious, his existential motivation. The greater or perhaps the most important characteristic of this new modality of damage, proposed in this paper, under the nomenclature of existential damage, is the widening of the Social Function of the institute of civil responsibility.

Keywords: Constitutional Civil Law. Existential Damage. Principle of Social Function in Civil Law.

Sumário: 1. Introdução. 2. O reconhecimento da pessoa como centro do ordenamento jurídico: a metodologia do Direito Civil Constitucional. 3. O dano existencial como uma nova modalidade de dano não patrimonial: ampliação da função social da responsabilidade civil, através da busca por uma reparação integral do dano à pessoa. 4. A interpretação sistemática do Código Civil Brasileiro e a aplicação do dano existencial em consonância com as previsões contidas em seus artigos. 5. Um dos maiores casos de dano existencial ocorrido no Brasil em que não houve a aplicação correta de sua terminologia. 6. Conclusão. 7. Referências. 


\section{Revista IBERC}

v. 2, n. 2, p. 01-22, mai.-ago./2019

www.responsabilidadecivil.org

\section{INTRODUÇÃO}

Apesar do Direito ter sempre contribuído para a criação de uma antropologia ${ }^{2}$, no sentindo de fazer com que, cada evento ou cada operação jurídica - em relação aos manifestos contidos nas cartas constitucionais - fosse desenhado sob o modelo de pessoa ${ }^{3}$, as primeiras Constituições, no entanto, foram influenciadas pela sociedade burguesa, nascida no Século XVII e desenvolvida no Século XIX, que viam no Código Civil, apenas uma forma jurídica, como um livro de ouro da sociedade que produzia e vendia mercadorias ${ }^{4}$.

A propriedade tinha força de direito exclusivo, aos poucos se confundia com o próprio conceito de liberdade, e afetava o sentido da igualdade, em si mesma, pois, quem não fosse proprietário de algo não teria liberdade, mas seria sujeito à propriedade de alguém.

O aumento da disparidade econômica, trazida pelo individualismo proprietário, instituiu de vez a primazia da moderna sociedade burguesa, implicando, praticamente, em uma constitucionalização da desigualdade. ${ }^{5}$

As Constituições liberais, no Brasil, repercutiam internamente tais valores, apenas estipularam o conceito do Estado mínimo, onde propriedade era tida como um valor necessário à realização da pessoa, portanto, outra coisa tais constituições não fizeram, a não ser estabelecer regras para as liberdades privadas, sem tratar das mesmas. As relações civis tinham na propriedade um valor individual e nada disciplinavam sobre as relações interpessoais. As regras ditadas pelos particulares imprimiam aos contratos celebrados o status de verdadeira lei entre as partes, devendo ser cumpridas, sob qualquer hipótese.

Os primeiros Códigos Civis foram influenciados pela codificação napoleônica e eram reconhecidos pelo seu forte aspecto patrimonial, representado nos contratos e na propriedade, como modo de circulação de riquezas. O Código Civil, que antes era visto como a "constituição do homem comum" (em especial, após o processo de codificação liberal), foi considerado o ramo do direito que mais se distanciava do direito constitucional, em clara oposição à Constituição política. ${ }^{6}$

Mesmo após mutações sociais, políticas e econômicas, a todos parecia que as relações jurídicas interpessoais e coexistenciais continuariam a permanecer intactas às alterações que

\footnotetext{
${ }^{2}$ Antropologia, aqui entendida, como o conhecimento do direito, em sua dimensão jurídica. Considerando ser, através da antropologia, que o direito constitui as figuras sociais. RODOTÀ, Stefano. La revoluzione della dignità. Napoli: La Scuola de Pitagora Editrice, 2013.

${ }^{3}$ A pessoa, por sua vez, vista não como resultado da simples constatação da natureza humana, mas como o resultado de um "jogo magistral", entre o espaço jurídico, que deveria acolhê-la, em sua conotação "natural", e a pessoa, como resultado de uma transformação pela qual a mesma passa, causada pelo próprio ordenamento jurídico, em um dado momento histórico e em um determinado período.

${ }^{4}$ RODOTÀ, Stefano. La revoluzione... p. 10.

${ }^{5}$ RODOTÀ, Stefano. La revoluzione... p. 11.

${ }^{6}$ LÔBO, Paulo. Constitucionalização do Direito Civil. Revista Informação Legislativa. Brasília, Senado Federal, v. 36, n. 141, p. 99-109, jan/março, 1999. Trecho da p. 100.
} 


\section{Revista IBERC}

v. 2, n. 2, p. 01-22, mai.-ago./2019

www.responsabilidadecivil.org

ocorriam ao seu redor. Mas, o modelo da propriedade privada, aos poucos, foi recebendo influências do direito do trabalhador. O homem trabalhador começava a ser visto, não simplesmente como proprietário de força laboral, que oferecia as mercadorias produzidas, mas como alguém que passava a integrar as várias Constituições, estas, por sua vez, progressivamente, passaram ter como fundamento o valor do trabalho.

O Direito Civil passava a seguir em direção à fundação constitucional das relações privadas. De sujeito de direito, na qualidade de cidadão, o indivíduo passou a ser pessoa, que não se submete tão somente às normas, mas que tem evidenciada sua vida individual e mantém uma imersão nas relações sociais.

A realidade social, distanciada dos fundamentos ideológicos do Estado Liberal e do individualismo jurídico, que inspiraram o Código Civil e as Constituições de 1824 e 1891, deram lugar ao Estado Social.

Depois da Segunda Guerra Mundial, diante da nova democracia ocidental, foram firmados compromissos políticos, em relação aos princípios fundamentais. Os valores de justiça social e de solidariedade, inerentes à ideologia do social, dominaram a realidade constitucional do século XX. Restituiu-se a figura do cidadão, fechando o longo parêntese da ditadura da guerra. Voltou a ser posta, de forma exclusiva e em realce, a atenção à liberdade e à igualdade. A relevância absoluta da dignidade, passava a se representar, pela da síntese do binômio liberdade e igualdade- reforçadas no fundamento democrático.

O Estado Social, presente a partir da Constituição de 1934 e das demais que se seguiram - democráticas e autoritárias - adotou como características essenciais a incorporação da organização política, dos direitos individuais, e da organização social e econômica, refletindo-se imediatamente nas relações privadas. ${ }^{7}$

O Estado Social passou a intervir no exato contexto em que a desigualdade fosse estabelecida pelo próprio Estado - no exercício de seu poder de império e de acordo com normas por ele predeterminadas - em relação ao particular, que deve permanecer a ele submisso. 0 Estado passou a ser chamado a intervir nas relações, que continuavam a ser estritamente civis e a ser visto como ente necessário à garantia da prevalência dos interesses coletivos, devendo evitar abusos e garantir o espaço público de afirmação da dignidade da pessoa humana. Para isso, a solidez do poder estaria, substancialmente no econômico e, relativamente, no político. ${ }^{8}$

Com reflexos inegáveis das novas dimensões materiais, inclusos na Constituição, o Estado - Providência passou a ser dirigir à regulação da ordem econômica e social, à limitação ao poder político e à projeção, para além dos indivíduos, da tutela dos direitos individuais e sociais.

\footnotetext{
${ }^{7}$ LÔBO, Paulo. Constitucionalização... p.102.

${ }^{8}$ LÔBO, Paulo. Constitucionalização... p. 101.
} 


\section{Revista IBERC}

v. 2, n. 2, p. 01-22, mai.-ago./2019

www.responsabilidadecivil.org

Dentro destes últimos direitos está o princípio da função social, cujo objetivo é alcançar o bem comum.

O cenário constitucional passou a ser dominado pelo desenvolvimento da pessoa humana e de suas formas associativas (formando os sujeitos coletivos), que tomados por ideologias sociais refletiam os valores de justiça social ou distributiva. Destacando-se, dentre tais valores, a defesa da liberdade, da igualdade material e a busca pelo reconhecimento de novos direitos, ainda não completamente adequados à codificação civil existente à época.

\section{O RECONHECIMENTO DA PESSOA COMO CENTRO DO ORDENAMENTO JURÍDICO: A METODOLOGIA DO DIREITO CIVIL CONSTITUCIONAL}

O reconhecimento de que a Constituição Federal é o vértice de harmonização, de elaboração e aplicação de qualquer legislação, causou uma importante mudança sob a perspectiva hermenêutica, atitude que resultou na sobriedade epistemológica em estabelecer o dever de interpretar o Código Civil à luz da Constituição.

No plano infraconstitucional, os sujeitos de direitos passaram a ser considerados iguais (formalmente), imperando, na prática, as desigualdades reais. A patrimonialização das relações civis passou a se tornar incompatível com os valores renovados pelo Estado Social e Democrático de Direito, que adotou a pessoa como fonte de todas as normas jurídicas.

O patrimônio deixou de ser absoluto, tendo papel derivado e prescindível, passando a servir à pessoa, em obediência ao princípio da função social.

A emancipação da pessoa humana no Direito Civil ressalta que, o indivíduo não é apenas titular de bens e de patrimônio, mas que a pessoa é o pressuposto indispensável da ordem jurídica e é a fonte da elaboração, da aplicação e da adequação das normas.

As normas devem ser criadas para servir de meio ao desenvolvimento da pessoa. A sociedade é o lugar destinado à evolução do indivíduo, é nela que a pessoa buscará extrair todas as suas próprias potencialidades. A sociedade contemporânea deve se voltar à evolução do humanismo e à realização dos valores existenciais da pessoa.

Ao adotar como prioridade os valores humanos, o texto constitucional assegurou não só o destaque à pessoa, mas fez ainda com que a perspectiva jurídica passasse à "repersonalização". 9

A igreja, o Estado e o Exército que estiveram sob a posição de domínio em relação às escolhas individuais, perderam seu espaço de regência para ao Direito. Este, tem o poder de

\footnotetext{
${ }^{9}$ LÔBO, Paulo. Constitucionalização... p. 59.
}

Revista IBERC, Minas Gerais, v. 2, n. 2, p. 01-22, mai.-ago./2019 


\title{
Revista IBERC
}

v. 2, n. 2, p. 01-22, mai.-ago./2019

www.responsabilidadecivil.org

garantir que cada pessoa tome suas próprias decisões, desde que assumam a responsabilidade de tê-las tomado, ante e pelos demais.

O Direito assume o papel de proteger e possibilitar que o homem faça livremente suas escolhas, de maneira individual ou mediante sua interação com o mundo em que vive, através da elaboração de seu projeto de vida. Segundo Bruno Miragem:

\begin{abstract}
Trata-se da repersonalização do direito civil, que, como consequência direta, observa a atenção e o reconhecimento de novos interesses da pessoa, e, mediante eventual violação destes, a identificação de novos danos. Em um primeiro momento, essa situação se apresenta pela afirmação apenas dos danos exclusivamente morais, ou seja, aqueles que produzem lesões ao estado anímico, de saúde ou psíquico da pessoa, como indenizáveis. Em nosso direito, eventual resistência quanto à indenização desses danos dissipou-se completamente a partir da vigência da Constituição de 1988, que expressamente prevê (art. $\left.5^{\circ}, \mathrm{V}\right)$. Ocorre que a partir daí, o traço de maior proteção da pessoa passou a indicar, igualmente, o reconhecimento de interesses específicos, dentro da abrangente classificação de danos patrimoniais e não patrimoniais lextrapatrimoniais, de modo a tutelar de maneira mais efetiva os interesses na hipótese de dano. Utiliza-se hoje, em diferentes sistemas jurídicos, de diversas classificações, como, por exemplo, dano existencial, dano à saúde, dano genético. ${ }^{10}$
\end{abstract}

A partir do conceito, do significado e do alcance do que é pessoa, o legislador passou a produzir as leis, que devem ter no sujeito, o objeto da mais ampla tutela jurídica. No final do século XX a Constitucionalização do Direito Civil Brasileiro tornou-se um fenômeno também doutrinário.Segundo Gustavo Tepedino:

\begin{abstract}
O percurso evolutivo da doutrina do direito brasileiro encontra-se intrinsicamente relacionado ao advento da Assembleia Constituinte, instalada em 1987, e ao clima do engajamento político que marcou o período de redemocratização do Brasil. Tal circunstância histórica propiciou intensa reflexão no âmbito do direito privado, influenciando de maneira decisiva sua produção acadêmica. Os constituintes trouxeram à baila questões que se encontravam na ordem do dia na sociedade brasileira dos anos 80 , demonstrando profunda preocupação coma democracia em construção. Revisitou-se, pouco a pouco, a partir de então, a metodologia do direito privado, mediante reconstrução de seus conceitos fundamentais, e procurou-se fazer do compromisso para com a pessoa humana e a justiça social a fonte de inspiração para produção intelectual, preocupação que se refletiva inevitavelmente na jurisprudência. ${ }^{11}$
\end{abstract}

Os juristas já se viam preocupados com as interferências trazidas pelas mudanças sociais e a adequação destas aos valores consagrados na Constituição de 1988. Esta buscou regular e controlar os poderes privados, tendo como seu objetivo a persecução da justiça material.

\footnotetext{
${ }^{10}$ MIRAGEM, Bruno. Direito Civil. Responsabilidade Civil. São Paulo: Saraiva, 2015. p. 30.

11 TEPEDINO, Gustavo. O Direito Civil-Constitucional e suas perspectivas atuais. In. O direito civil contemporâneo. Novo problema à Luz da Legalidade Constitucional. Anais do Congresso Internacional de Direito Civil - Constitucional da Cidade do Rio de Janeiro. São Paulo, Atlas, 2008. pp. 356-357.
}

Revista IBERC, Minas Gerais, v. 2, n. 2, p. 01-22, mai.-ago./2019 


\section{Revista IBERC}

v. 2, n. 2, p. 01-22, mai.-ago./2019

www.responsabilidadecivil.org

O Estado passou a destinar a elaboração de suas leis a serviço da proteção e desenvolvimento da pessoa humana (o indivíduo em si considerado) e do bem comum (sob o ponto de vista da solidariedade).

No dizer de Maria Cristina De Cicco: "[...] Vale dizer, que estão no centro do sistema e representam o eixo em torno do qual gira todo ordenamento, com a consequente subordinação das relações patrimoniais aos valores existenciais"12.

A lógica da justiça retributiva foi substituída pelo distributivismo e a responsabilidade civil foi inspirada nos princípios da dignidade da pessoa humana, na solidariedade social e na isonomia substancial. Além de ter representado uma conquista determinantemente transformadora de toda norma jurídica privada, a consagração da dignidade da pessoa humana, em último grau, consolidou também o predomínio das situações jurídicas existenciais, sobre as relações jurídicas patrimoniais.

Em se tratando dos fundamentos do Direito Civil, estes foram elevados ao status constitucional, baseados na promoção da justiça social e na solidariedade. Já os fundamentos jurídicos das relações privadas foram representados na personalidade, na família, no contrato, na propriedade e no dano.

O direito Civil-Constitucional foi consagrado através da hermenêutica extensiva dos princípios e dos direitos fundamentais da Constituição ao Código Civil, migração que resultou na maior efetividade dos direitos já assegurados civilmente. ${ }^{13}$

O civilista, ao verificar e observar as categorias fundamentais da Constituição, passou a tê-la como referência. O direito civil passou a aplicar concretamente os valores, os princípios e as normas constitucionais às relações privadas e ao projeto de vida em comum, deixando de levar em consideração os locais reservados às pessoas, em razão de seu patrimônio. Com relação ao Direito Civil- Constitucional, afirma Maria Celina Bodin:

Uma das características fundantes do direito civil- constitucional é a aplicação
direta dos princípios constitucionais às relações privadas. Isto significa dar
grande peso aos princípios no processo de interpretação -aplicação do direito.
Sua importância decorre, evidentemente, do reconhecimento do caráter
normativo dos princípios ao lado das regras, na já consagrada distinção de
Dworkin. No contexto atual, dito pós-positivista, os princípios são o pedestal

${ }^{12}$ CICCO, Maria Cristina De. A pessoa e o Mercado. In O direito civil contemporâneo. Novo problema à Luz da Legalidade Constitucional. Anais do Congresso Internacional de Direito Civil - Constitucional da Cidade do Rio de Janeiro. São Paulo: Atlas, 2008. p. 106.

${ }^{13}$ FACHIN, Luiz Edson. A Construção do Direito Privado Contemporâneo na experiência Crítico-Doutrinária brasileira a partir do Catálogo Mínimo para o Direito Civil- Constitucional no Brasil. Gustavo Tepedino (org). Direito Civil Contemporâneo. São Paulo: Atlas, 2008. p. 17. 


\title{
Revista IBERC
}

v. 2, n. 2, p. 01-22, mai.-ago./2019

www.responsabilidadecivil.org

normativo do sistema. Eles concretizam os valores reputados, ou melhor, democraticamente estabelecidos como os mais essenciais àquela comunidade. ${ }^{14}$

A interpretação do Código e das leis civis se sujeita aos valores, aos princípios e às normas constitucionais, devendo ter como objetivo o alcance o projeto de vida de cada uma das pessoas que compõem a sociedade, impostos constitucionalmente. Nas palavras de Perlingieri:

\begin{abstract}
Os principais pressupostos teóricos da doutrina do direito civil na legalidade constitucional - concebida como consequência inevitável da incidência do constitucionalismo contemporâneo sobre o fenômeno da produção legislativa e, particularmente, das codificações - referem-se: (a) à natureza normativa das constituições; (b) à complexidade e ao caráter unitário do ordenamento jurídico e ao pluralismo das fontes do direito; (c) a uma renovada interpretação jurídica com fins aplicativos. ${ }^{15}$
\end{abstract}

A aplicação dos princípios constitucionais e a metodologia utilizada na sua ponderação, sob a ótica dos estudos da teoria geral do direito, determinaram a mudança da antiga concepção cristalizada da Constituição, como carta política endereçada apenas, ao legislador. ${ }^{16}$

A aplicação da regra específica ao fato apresentado cede lugar e se complementa pelo procedimento de avaliação do intérprete, feita caso a caso, subordinando-a aos princípios jurídicos nele envolvidos. A proteção dos valores existenciais passa a ser o norte da nova ordem pública instaurada pela Constituição. Todas as situações jurídicas, portanto, passaram a ser comprometidas com a realização do programa constitucional. ${ }^{17}$

As normas devem ser produzidas e direcionadas ao indivíduo, e ao seu pleno desenvolvimento em sociedade. Indivíduo é visto não só em sua individualidade, mas como um alguém que interage com os demais seres humanos e com o próprio Estado.

O desenvolvimento da pessoa no mundo em que vive passa a ser o eixo e o centro gravitacional das normas e dos princípios constitucionais. Não há redução quantitativa dos espaços da autonomia privada, mas sim uma forte intervenção do poder público, vinculado à opção valorativa constitucional. Ao legislador, à magistratura e à doutrina competem à construção de bases objetivas para a realização de um direito civil convergente à tabua de valores

\footnotetext{
${ }^{14}$ MORAES, Maria Celina Bodin de. Perspectiva a partir do Direito Civil-Constitucional. In O direito civil contemporâneo. Novo problema à Luz da Legalidade Constitucional. Anais do Congresso Internacional de Direito Civil - Constitucional da Cidade do Rio de Janeiro. São Paulo, Atlas, 2008. pp. 38-39.

${ }^{15}$ PERLINGIERI, Pietro. A doutrina do Direito Civil na Legalidade Constitucional. In O direito civil contemporâneo. Novo problema à Luz da Legalidade Constitucional. Tradução de Carolina Tomasi e Jõao Bosco Medeiros. Anais do Congresso Internacional de Direito Civil - Constitucional da Cidade do Rio de Janeiro. São Paulo, Atlas, 2008. pp. 38-39.

${ }^{16}$ MORAES, Maria Celina Bodin de. Danos à pessoa uma Leitura Civil- Constitucional dos Danos Morais. $4^{\mathrm{a}}$ tiragem. São Paulo: Renovar, 2009. p. 233.

${ }^{17}$ TEPEDINO, Gustavo. O Direito... p. 5.
} 


\section{Revista IBERC}

v. 2, n. 2, p. 01-22, mai.-ago./2019

www.responsabilidadecivil.org

axiológicos, previstos constitucionalmente, tendo como base técnicas os critérios interpretativos e uma dogmática renovada, capazes de atender aos desafios suscitados pelo sistema de fontes.

A antiga concepção individualista-patrimonialista, concentrada mais na proteção dos interesses materiais (valores patrimoniais), que na pessoa em si considerada, cedeu lugar aos interesses existenciais. A partir do existencialismo, o homem passou a ser colocado em posse do que ele "é", a preocupação passa a voltar-se para a sua existência. A partir de sua existência, o homem pôde determinar a sua essência, ele estará representado naquele que quer se tornar, aquele que projeta vir a ser. ${ }^{18}$

O mundo exterior, por sua vez, passa a ser visto como o espaço onde o homem desenvolve sua existência, onde estão os "outros" e as "coisas". As decisões, as convenções, as crenças, os desejos, os sonhos e, em um segundo momento, a concretude das decisões, livremente assumidas pelas pessoas, são reflexos das suas realizações externas. Todas essas, assim ditas liberdades, distinguirão os homens e as suas responsabilidades em sociedade. ${ }^{19}$

Projetivo e criador o homem vive para "ser", mesmo sobre todos os determinismos e condicionamentos que pesam sobre ele. É dentro do seu espaço de liberdade, variável no tempo e na sociedade, que ele é responsável. Por ser livre é que ele assume o projeto da sua vida e de seus valores internos, percebendo-os, vivenciando-os para, a partir daí, condicionar-se a valorálos externamente, quando em contato com os que coexistem com ele.

Cada uma das pessoas é única e idêntica apenas a si mesma. Cada pessoa livre é, em última instância, apesar de submetida a todos os condicionamentos, responsável pelo seu destino, pelo seu exclusivo "o que fazer na vida", determinante do que será o seu histórico temporal. Sem projeto de vida, a pessoa careceria de critérios de vida, de paradigmas de conduta e do discutir existencial. ${ }^{20}$

Ao adotar, como prioridade, os valores humanos, o texto constitucional assegurou que a perspectiva jurídica passasse à transição, rumo à repersonalização. A repersonalização afirma a primazia do valor da pessoa humana (dentro de um contexto social), sendo a justiça o valor primário da vida em comunidade e do ordenamento jurídico social. Este último, tem como base, o bem social comum, confirmando a realidade existencial da pessoa como um fim em si mesma. $\mathrm{O}$ homem, portanto, é juridicamente protegido enquanto um valor e não apenas como um ser sujeito à normatividade.

\footnotetext{
${ }^{18}$ É a partir de sua existência, que ele se envolve com a humanidade e como um todo. SARTRE, Jean Paul. O existencialismo é um humanismo. Rio de Janeiro: Vozes, 2010. p.19-20.

${ }^{19}$ SESSAREGO, Carlos Fernández. Protección Juridica de la Persona. Lima: Publicaciones de la Universidad de Lima. 1. ed., 1992. p.19

${ }^{20}$ SESSAREGO, Carlos Fernández. Protección ... p. 23.
} 


\section{Revista IBERC}

v. 2, n. 2, p. 01-22, mai.-ago./2019

www.responsabilidadecivil.org

$\mathrm{Na}$ tentativa de conciliar o individualismo com o coexistencialismo, é que se sustenta a proteção unitária e integral da pessoa humana, em uma dimensão de solidariedade. ${ }^{21} \mathrm{O}$ ser humano é um ser social e coexistencial. O social não é algo que se encontra, previamente, externo ao indivíduo, ele está presente quando um ser encontra-se em comunicação com os demais, só existe o "eu" se existe "todos os outros".

Imersa em uma situação jurídica subjetiva e intersubjetiva, portando de deveres e de direitos, cada pessoa humana tem uma estrutura existencial apta a determinar a necessidade de uma tutela unitária e integral, onde a mesma possa ser vista como unidade referencial, ou seja, como ponto de partida e termo final do ordenamento jurídico.

$\mathrm{Na}$ medida em que os direitos são exercidos em um contexto social, em coordenação ou em relação aos direitos subjetivos dos demais membros da sociedade, é possível a concretização de uma realidade coexistencial, os direitos, dotados de uma função social, conduzem à intersubjetividade do relacionar-se humano.

É na solidariedade que os direitos subjetivos têm, como limite natural e concreto, o direito e o interesse dos demais, como princípios gerais do direito. A proteção jurídica da pessoa humana tem como fundamento sua qualidade ontológica, pelo que ela é em si, enquanto sujeito de direito, como bem supremo da sociedade e do Estado. A tutela jurídica objetivará o indivíduo em suas relações existenciais, na interferência em que o seu coexistir produzir em sociedade e na sua dinamicidade em face à unidade do ordenamento jurídico.

Portanto, o dano que atinge o indivíduo, considerado membro de uma sociedade em que vive e com a qual se relaciona, onde ocorre seu desenvolvimento pessoal, é considerado o centro da reparabilidade civil sob o qual se funda a Constituição da República.

Os movimentos sociais influenciaram a evolução da responsabilidade civil, levando-se a crer que, por serem vários os danos que emergem contra a pessoa, haveria a necessidade da amplitude da reparação civil, para que ela possa cumprir a função social de ser, dentro da possibilidade real, a mais integral possível.

É no momento da interpretação da norma aplicável ao caso concreto que o juiz, baseado na equidade, deverá dar a concretização aos princípios e aos direitos fundamentais, previstos constitucionalmente. ${ }^{22}$

A partir de uma aplicação concreta, aberta e plural das normas é que se respeitaria, sobretudo, a diversidade, desprovendo-a das chamadas verdades insertas em dogmas. ${ }^{23}$

\footnotetext{
21 SESSAREGO, Carlos Fernández. Protección ... p. 27.

22 BILBAOS UBILLOS, Juan María. Direito Civil Contemporâneo. In. TEPEDINO, Gustavo (org). São Paulo: Atlas, 2008. p. 468.

${ }^{23}$ MORAES, Maria Celina Bodin de. Danos... p. 21.
} 


\section{Revista IBERC}

v. 2, n. 2, p. 01-22, mai.-ago./2019

www.responsabilidadecivil.org

O princípio da dignidade da pessoa humana, como cláusula geral de tutela da pessoa, foi direcionado à prevenção e à reparação dos danos causados às pessoas, e teve sua tutela ampliada às situações jurídicas existenciais. A indenização resultante do dano nem sempre resultaria na sua monetarização, porque há danos de natureza essencialmente existencial. ${ }^{24}$

O Direito deve tutelar a pessoa no que ela tem de mais valioso, pelo o que ela significa e pelo que ela é. A pessoa não é apenas um Ser que vive para a sociedade, que gera riquezas, que produz trabalho e que é fonte de utilidades. Como sanção civil a ser aplicada ao autor do dano há a aplicação da indenização ou da reparação em dinheiro, podendo ocorrer a retratação do agente, o direito de resposta, multa e a busca e apreensão, auferível a partir das consequências do dano sofrido ou de tudo que razoavelmente deixou de se obter proveito.

Diante dos principais detentores de capital, devem ser asseguradas pelo Estado condições ambientais, físicas, políticas e econômicas para que a pessoa possa influenciar e ser influenciada pelas reformas necessárias ao seu amplo desenvolvimento e realização. Em certos casos, o dano à pessoa pode gerar consequências apreciadas economicamente e ressarcidas monetariamente, e pode não ter efeitos patrimoniais negativos, mas somente morais. Os danos não suscetíveis de valoração econômica repercutem diretamente sobre a pessoa em seus direitos invioláveis, essenciais e inatos, que constituem sua personalidade.

Pelo exposto, foi necessária a superação do modelo de reparação civil, deixando-se de lado aquele modelo que apenas reproduzisse o que deveria ser reparado economicamente (representado pelos danos patrimoniais), por ser este extraído sob uma ótica materialista e exclusivamente econômica do direito, logo, a concepção economicista de pessoa cedeu lugar à abordagem da natureza do homem enquanto si mesmo, contemplando todos os seres humanos, seja ele ou não gerador de riquezas.

É importante perceber que, nesta transição, a responsabilidade civil se direcionou, essencialmente, à prevenção e à reparação das lesões à pessoa, portanto, a sua proteção contra qualquer tipo de dano. Razão pela qual defende-se, no presente artigo, a necessidade da inclusão do dano existencial, como uma espécie de dano não patrimonial, nosso ordenamento jurídico, pois o modelo vanguardista que estabelece o dualismo entre o dano material e moral é insuficiente a servir como mecanismo de reparação civil, apto a contemplar o ressarcimento da vítima.

A realidade reclama por uma nova modalidade de dano, conhecida pela doutrina internacional como dano existencial, no qual está inserido o dano ao projeto de vida ou lost enjoyment of life e o dano à vida de relações, como se passará a analisar.

\footnotetext{
${ }^{24}$ MORAES, Maria Celina Bodin de. Danos... p. 19-21.
} 


\title{
Revista IBERC
}

v. 2, n. 2, p. 01-22, mai.-ago./2019

www.responsabilidadecivil.org

\section{O DANO EXISTENCIAL COMO UMA NOVA MODALIDADE DE DANO NÃO PATRIMONIAL: AMPLIAÇÃO DA FUNÇÃO SOCIAL DA RESPONSABILIDADE CIVIL ATRAVÉS DA BUSCA POR UMA REPARAÇÃO INTEGRAL DO DANO À PESSOA}

Aos poucos as categorias dos danos não se destacavam mais pela sua qualidade, mas pela proporção e dimensão do evento danoso e de como este se reflete no ser, nas coisas necessitando de um maior assistencialismo e nas pessoas que convivem com a vítima da lesão. ${ }^{25}$

A proteção aos bens não patrimoniais é uma questão que acompanha o processo civilizatório e, quanto mais desenvolvido for o processo civilizatório, maior é a consciência social. Quanto maior for a consciência social, maior será a exigência quanto à ampliação de tutela dos bens juridicamente protegidos. ${ }^{26}$

Um dano não pode deixar de ser reconhecido ou de ser aplicado por não haver previsão legal explicita, de forma que, qualquer lesão causada à pessoa deve ser ressarcida, ainda que para isso seja necessária a criação de uma nova categoria de proteção de danos à pessoa. Para Silvio Romero Beltrão:

\begin{abstract}
O problema dos direitos da personalidade atípicos pode ser resolvido satisfatoriamente pela adoção do numerus apertus de direitos especiais da personalidade, tendo como ponto de partida a cláusula geral. Ou seja, a partir da cláusula geral é possível delimitar novos direitos da personalidade, fundamentando o novo tipo nas manifestações da dignidade da pessoa humana. Contudo, não se quer atribuir à cláusula geral o sentido de direito pertencente à natureza humana, como instrumento de reação ao poder estatal, tal como advertia Adriano de Cupis, onde o direito inato não tem como consequência o controle dos poderes do Estado; tal atribuição é da declaração dos direitos do homem e do cidadão. $O$ fundamento dos direitos especiais da personalidade está na cláusula geral, como emanação do princípio da tutela da dignidade da pessoa humana, com a imposição de que todas as manifestações desta sejam juridicamente tuteladas. Assim, o reconhecimento do regime aberto dos direitos da personalidade fundamenta-se no princípio da dignidade da pessoa humana, onde todos devem respeitar esse princípio, objetivando sua caracterização como direito absoluto. ${ }^{27}$
\end{abstract}

A gravidade, o momento em que o dano foi causado, o cerceamento, o impedimento ou modificação do projeto de vida e dos relacionamentos sociais da vítima, devem ser julgados mediante a apresentação de uma prova concreta, que ateste a permanência e a irreversibilidade do dano existencial, de modo a torná-lo plenamente justificável de ser aplicado pelo ordenamento jurídico brasileiro, através da doutrina, e da jurisprudência.

\footnotetext{
25 JONAS, Hans. O princípio responsabilidade. Ensaio de uma ética para a civilização tecnológica. Rio de Janeiro: Contraponto Editora PUC Rio, 2006. p. 166.

${ }^{26}$ CHRISTANDL, Gregor. I/ diritto privato oggi. La risarcibilità del danno esistenziale. Milano: Giuffrè Editore, 2007. p. 69.

${ }^{27}$ BELTRÃO, Sílvio Romero. Direitos da personalidade. De acordo com o novo Código Civil. Atlas: São Paulo, 2005. p. 55.
}

Revista IBERC, Minas Gerais, v. 2, n. 2, p. 01-22, mai.-ago./2019 


\section{Revista IBERC}

v. 2, n. 2, p. 01-22, mai.-ago./2019

www.responsabilidadecivil.org

Ao analisar o dano à pessoa, comprova-se que as modalidades de danos existentes não são mais suficientes à reparação integral da vítima. O novo fenômeno do dano à existência, ou dano existencial, tomou cada vez mais corpo, pois, a pessoa visa a concretização de um projeto de vida de caráter global, que não se exaure no desenvolvimento do aspecto exclusivamente econômico.

O alcance da proteção da pessoa na Constituição e a proteção dos valores de caráter pessoal são postos como objetivos prioritários à elaboração das normas, por meio dos quais se tem em vista a garantia do desenvolvimento da personalidade e o pleno desenvolvimento da pessoa humana.

Os limites da tutela de certas situações, além do prejuízo à integridade psicofísica, passam a ser questionados. Pois, começam a surgir novos danos à pessoa, a singularidade destes novos danos emergem como decorrência do complexo de ligações e interligações entre as pessoas pertencentes a uma sociedade, em um determinado tempo e em um dano momento histórico. Ações de indenizações, cujas queixas eram até então desconhecidas, terminaram chegando aos tribunais.

O dano à pessoa não se restringe ao dano moral e não é sinônimo de dano não patrimonial. $O$ interesse pessoal protegido e as consequências que advierem do prejuízo causado ao bem tutelado fazem parte da liquidação do dano, e devem ser levados em consideração. ${ }^{28}$

A lesão permanente da integridade psicofísica, sob o plano da existência da pessoa, induz uma piora na qualidade de vida, que vai além da sua permanência no tempo, representa muito mais que um estado de angústia, esta piora na qualidade de vida da vítima representa um dano às relações sociais, sendo também pública a natureza do interesse protegido.

O danno esistenziale passou a integrar a tipologia da responsabilidade civil italiana, a par e além do dano moral, em razão de sua extensão, de sua permanência e da natureza dos direitos violados. Um dano cujo reconhecimento é indispensável à proteção e ao respeito ao ser humano, em sua tranquilidade existencial, e em suma, em sua dignidade. A Itália foi o primeiro país a reconhecer judicialmente este tipo de dano, seguido depois pela doutrina italiana e hoje defendido por alguns raros autores brasileiros, porém sem a profundidade com que aqui será tratado.

O dano existencial é uma nova categoria de dano não patrimonial, ao lado do dano moral e com este não se confunde, pois, enquanto o dano moral é inerente à condição humana; já o dano existencial está representado na lesão dos "afazeres domésticos", das "atividades

\footnotetext{
28 MORAES, Maria Celina. Perspectiva a partir do Direito Civil-Constitucional. In: O direito civil contemporâneo. Novo problema à Luz da Legalidade Constitucional. Anais do Congresso Internacional de Direito Civil - Constitucional da Cidade do Rio de Janeiro. São Paulo: Atlas, 2008. p. 74.
} 


\title{
Revista IBERC
}

v. 2, n. 2, p. 01-22, mai.-ago./2019

www.responsabilidadecivil.org

realizadoras da pessoa", do "perturbamento da vida cotidiana", de um "diverso relacionamento com o tempo e espaço", da "quantidade da vida" ou perda de "ocasiões felizes"

Enquanto o dano moral é um "sentir"; o dano existencial é mais que um "fazer", aliás é um "não poder mais fazer", um "dever agir de outro modo". O dano moral está ligado à natureza "interior" da pessoa, à esfera emotiva; destina-se à consideração do que se sofreu, das angústias. O dano existencial, por sua vez, relaciona-se com o "externo", o tempo e espaço da vítima; traz uma reviravolta forçada nos compromissos anteriormente firmados ou que ainda estavam por vir a ser estabelecidos.

Do 'fazer não remunerado' da pessoa e do seu existencialismo surge a necessidade pela busca de uma terceira modalidade de dano, para além do dano moral, porque a pessoa não vale pelo que ela produz e sim pelo que é, em sua existência. É através da existência que a pessoa se projeta e inicia a formação dos vínculos sociais.

Com o transcurso do tempo fica mais clara a necessidade de se ampliar a prevenção e a repressão em relação aos danos causados à pessoa, em defesa da dignidade humana e da persecução do bem comum. Torna-se perceptível que a reparação integral do dano causado à pessoa, que dá sentido a todo sistema ressarcitório precisa ser revisto e atualizado a fim de se adequar a regra, segundo a qual, os interesses coletivos, representados na prevenção e repressão aos danos estejam acima interesse individual de exercer, por vezes, de forma ilimitada, o seu livre arbítrio.

Nos dias atuais verifica-se que o dano moral é incapaz de contemplar e reparar todas as lesões causadas às pessoas. Assim, diante da necessidade da busca por um maior atendimento à realização da função social, no que tange ao instituto da responsabilidade civil, faz-se imprescindível a elaboração de dispositivos de lei e a aplicação pelos juízes e juristas do dano existencial, como uma nova modalidade de dano capaz de ampliar as possibilidades de atender aos princípios da dignidade da pessoa humana e da solidariedade.

Não há razão lógica para eventual restrição quanto a possibilidade de indenização ao dano não patrimonial. Pelo contrário, como afirma Caio Mário da Silva Pereira:

\begin{abstract}
$\mathrm{Na}$ atualidade o dano adquiriu papel central na responsabilidade civil. A consagração constitucional dos princípios da dignidade da pessoa e da solidariedade social associada ao acelerado desenvolvimento tecnológico, deslocou a ênfase da conduta do agente para o dano ressarcível, assistindo-se ao surgimento de formidável tipologia de novos danos, na esteira do incremento de riscos e do potencial danoso trazido pelas novas inovações. Não parece exagerada, neste cenário à era dos danos. ${ }^{30}$
\end{abstract}

\footnotetext{
${ }^{29}$ Expressões utilizadas indiscriminadamente pela doutrina italiana, reunidas com a finalidade de se fornecer uma visão geral das nomenclaturas aplicáveis quando da aplicação do dano existencial.

${ }^{30}$ PEREIRA, Caio Mário da Silva. Responsabilidade Civil. Atualizador: Gustavo Tepedino. São Paulo: Saraiva, 2016. p. 53.
} 


\section{Revista IBERC}

v. 2, n. 2, p. 01-22, mai.-ago./2019

www.responsabilidadecivil.org

O dano existencial, de natureza hedonista, está consubstanciado na lesão ao prazer de viver do indivíduo, que se realiza e se desenvolve na sociedade em que está inserido. $\mathrm{O}$ dano existencial é provocado em um determinado momento da vida da vítima, mas se irradiará por toda ela - a partir do evento danoso em diante - quer na sua relação existencial, quer nas suas relações com seus familiares, possivelmente com o seu cônjuge ou seu companheiro(a), em relação ao seu (s) empregador (es) e nas suas relações sociais externas através das quais a pessoa se relaciona com o que existe ao seu redor.

Partindo-se de uma interpretação extensiva dos direitos fundamentais, previstos na Constituição Federal, foi possível verificar que o dano existencial pode ser inserido no ordenamento jurídico brasileiro, como uma nova modalidade de dano não patrimonial, pertencente à teoria dos direitos de danos.

O dano existencial é representado por dois elementos constitutivos, o dano ao projeto de vida e o dano à vida em relações, abaixo relacionados.

a) Dano ao projeto de vida (chamado ainda de: prejudice d'agrément - perda da graça ou lost pleasure of life): no dano ao projeto de vida está inserida toda e qualquer lesão que venha a comprometer a liberdade de escolha, que possa vir concretamente destruir o que a pessoa lesada idealizou para sua realização enquanto ser humano. Toda e qualquer pessoa tem um projeto, voltado à sua autorrealização ${ }^{31}$.

Precisamente por viver no tempo, cada um busca divisar seu projeto de vida. O vocábulo "projeto" encerra em si toda uma dimensão temporal. O conceito de projeto de vida tem um valor essencialmente existencial. É dizer, no marco da transitoriedade da vida, que cada um pode fazer as opções que the parecem acertadas ao seu alcance, em busca da realização de seus ideais.

A busca da realização pelo projeto de vida revela um alto valor existencial, capaz de dar sentido à vida de cada um. A ruptura dessa busca, por fatores alheios, como a violência, a injustiça, a discriminação, que alterem e destruam arbitrariamente o projeto de vida de uma pessoa, reveste-se de particular gravidade, - e o Direito não pode se quedar inerte a isso.

O projeto de vida dependerá do relacionamento entre as pessoas humanas, como um ser que se relaciona com os outros seres no mundo ou seres coexistenciais, da interação de uma pessoa com as outras, da forma que se inserem no mundo, de suas adaptações e de suas readaptações às atividades desenvolvidas em conjunto na sociedade em que vive.

O projeto de vida é o direcionamento que uma pessoa dá a suas escolhas interiores, com a finalidade de assegurar sua concretude. As escolhas interiores serão desenvolvidas de

\footnotetext{
${ }^{31}$ A autorrealização decorre de um lento e complexo processo do despertar, desenvolver e amadurecer psicológicos da pessoa, no que diz respeito às suas potencialidades íntimas e latentes no ser humano. Surge como consequência das experiências e realizações ético-morais, estéticas, religiosas, artísticas e culturais do indivíduo. Equivale a todo esforço direcionado para a realização do ser, do profundo empoderamento de si mesmo, enquanto pessoa.
} 


\section{Revista IBERC}

v. 2, n. 2, p. 01-22, mai.-ago./2019

www.responsabilidadecivil.org

acordo com o contexto espaço-temporal em que o ser se encontra inserido, nas metas traçadas, nos objetivos e nas ideias intrínsecas que serão responsáveis por dar sentido à sua própria existência.

O dano ao projeto de vida é um dano especial, transcende ao que se conhece e se designa como integridade psicossomática da pessoa. É um dano radical e profundo que compromete as expectativas existenciais do indivíduo. O dano ao projeto de vida é visto como um dano em consequência, ele causa a perda do sentido que a pessoa empregou para seu viver e se relacionar com as demais pessoas e coisas. $O$ dano que frustra esse destino (impede a sua plena realização), obriga a pessoa a resignar-se com o futuro que lhe fora imposto como consequência do dano em si.

b) Dano à vida em relações: o indivíduo, como ser humano, pode, uma vez inserido em diversas relações interpessoais, nos mais diversos ambientes e contextos, vir a estabelecer sua vivência e seu desenvolvimento pela busca constante do êxito no seu projeto de sua vida, do gozo dos direitos inerentes à sua personalidade, de suas afinidades e de suas atividades. A pessoa objetiva seu crescimento através da continuidade no contato, por meio dos processos de diálogo e de dialética com os demais membros, que participam com ele da vida em sociedade.

O dano existencial, em medida mais ou menos relevante, causa uma alteração que vem se demonstrando cada dia, de forma mais substancial, nas relações familiares, sociais, culturais, afetivas, etc. $\mathrm{O}$ dano existencial corresponde, desta forma, todo acontecimento que venha a incidir de forma negativa, sobre o cotidiano, sobre as atividades normalmente desempenhadas pela pessoa humana, suscetível de vir a repercutir, de forma consistente e permanentemente, sobre a sua existência.

Destaca-se que há casos em que o pagamento não é a melhor forma de reparar, ressarcir ou indenizar, pois a sentença pode indicar a retratação pública, a fixação de cotas periódicas a serem pagas à pessoa lesada (podendo ser vitalícia), o fornecimento de um tratamento adequado à lesão causada, o fornecimento de assistência médica e acompanhamento do quadro de saúde, o reenquadramento em outra função, o fornecimento de emprego, etc.

\section{A INTERPRETAÇÃO SISTEMÁTICA DO CÓDIGO CIVIL BRASILEIRO E A APLICAÇÃO DO DANO EXISTENCIAL EM CONSONÂNCIA COM AS PREVISÕES CONTIDAS EM SEUS ARTIGOS}

Apesar do Código Civil brasileiro não dar tratamento explícito ao dano existencial, da interpretação sistemática da legislação jurídica pátria, foram possíveis ser encontradas fundamentações legais à sua aplicação. 


\section{Revista IBERC}

v. 2, n. 2, p. 01-22, mai.-ago./2019

www.responsabilidadecivil.org

Portanto, a seguir, citem-se como premissas conclusivas para a aplicação do dano existencial os seguintes artigos do Código Civil Brasileiro, seguindo-se das justificativas apresentadas:

a) O artigo 949 trata da lesão ou ofensa à saúde, cuja indenização do ofendido será calculada de acordo com as despesas do tratamento e dos lucros cessantes, até ao fim da convalescença, além de algum outro prejuízo que o ofendido prove haver sofrido.

Ao se referir às despesas com o tratamento e aos lucros cessantes, o código tutelou em parte uma indenização que pode ser liquidada através da demonstração do que foi gasto com o tratamento e do valor relativo a tudo que a vítima deixou de lucrar devido às lesões. Sob este ponto de vista é presente o aspecto material do dano; mas, ao tutelar a possibilidade de "algum outro prejuízo que o ofendido prove haver sofrido", pode-se incluir a aplicação do dano existencial.

Como exemplo, uma pessoa hemofílica que adquire o vírus HIV através de uma transfusão de sangue contaminado, por erro do banco de sangue, não terá apenas lucros cessantes, mas o agravamento de sua saúde e a aquisição de uma doença incurável que pode limitar a vítima em suas atividades mais comuns e ainda conduzi-la a uma vida de discriminação na sociedade em que vive.

Ou, por exemplo, se em decorrência de uma vacina fornecida e aplicada por meio de uma campanha nacional de saúde, a pessoa contrair um estado de paralisia total do corpo, de maneira comprovadamente irreversível, não haverá apenas um dano moral ou dano estético, e sim um dano existencial, nos termos do mencionado artigo ao destacar a expressão "além de algum outro prejuízo que a vítima prove ter sofrido".

Ademais, o dano existencial para ser reconhecido como tal e para que seja indenizado, depende de prova da sua existência, do direito lesado e da extensão do prejuízo causado.

b) $O$ artigo 950, trata da indenização que tenha como consequência um dano que resulte na diminuição da capacidade laboral, nos casos em que o ofendido não possa mais exercer o seu ofício ou profissão, devendo a indenização incluir as despesas com tratamento e lucros cessantes até ao fim da convalescença, mais pensão correspondente à importância do trabalho para que ficasse inabilitado, ou da depreciação que ele sofreu.

O Código se preocupou em proteger a vítima capaz de produzir atividade remunerada, recompondo o seu patrimônio em razão do que ela perdeu e do que deixou de ganhar. Porém, mais que isto, a indenização deve ocorrer até o fim da convalescença, se esta for permanente. A indenização, nos casos de dano existencial, deve, então, ser por toda a vida daquele que sofreu o dano.

Abrindo abertura para a aplicação do dano existencial, pois se não houver a convalescença da vítima, a indenização será paga de modo continuado no tempo. Mas esta indenização será indefinida, possibilitando as pensões vitalícias, como forma implícita de 


\section{Revista IBERC}

v. 2, n. 2, p. 01-22, mai.-ago./2019

www.responsabilidadecivil.org

denominação do dano existencial, assim, por exemplo, se alguém vem a perder a visão em razão de uma substância - que, devendo estar isolada do contato humano, encontrava-se em local inapropriado - altamente nociva à saúde a qual indevidamente (sem culpa sua) teve contato, não haverá convalescência para sua cegueira, não se trata de mera aplicação de dano estético ou de dano moral, mas de um dano existencial.

No caso mencionado acima há exata aplicação do art. 950 do CC, pois a vítima não pode mais exercer o seu ofício e, portanto, tem direito à pensão correspondente à importância do trabalho para o qual se inabilitou.

Conclui-se que o Brasil já aplica o dano existencial, nos casos em que a condenação se dá por meio de pensão vitalícia. Apesar de não ser utilizada a terminologia "dano existencial" a indenização através da pensão vitalícia é um exemplo real do dano existencial a ser reconhecido e aplicado implicitamente no nosso ordenamento jurídico.

c) O artigo 951, versa sobre a indenização devida por aquele que, no exercício de atividade profissional, por negligência, imprudência ou imperícia, causar a morte do paciente, agravar-Ihe o mal, causar-Ihe lesão, ou inabilitá-lo para o trabalho.

Ao estabelecer a necessidade de inabilitação da vítima para o trabalho, para fins de indenização, o Código Civil ressaltou novamente os lucros cessantes, ou seja, um dano à capacidade de gerar renda, mas também previu a condenação ao pagamento de uma indenização a ser aplicada ao profissional de saúde que inabilite a pessoa para o trabalho.

No ano de 2016, um avião que transportava um time de futebol brasileiro e sua delegação caiu, matando quase a totalidade de seus passageiros. O laudo técnico da ANAC comprovou que o acidente aéreo se deu por negligência da companhia aérea, em razão da insuficiência de combustível, levando a aeronave a colidir ao solo antes de sua chegada no local do pouso.

Uma das vítimas do acidente aéreo foi goleiro brasileiro do time da chapecoense, sobrevivente à queda do avião teve sua perna amputada, ele não poderá mais jogar, nas mesmas condições e da mesma maneira que fazia antes, profissionalmente, por toda a sua vida.

Caso semelhante ou pior é o do paciente que, ao se operar de uma hérnia inguinal teve o seu testículo esquerdo atrofiado, primeiro veio a ficar impotente e depois em nova cirurgia teve o mesmo amputado, perdendo definitivamente a possibilidade de projetar-se como pai biológico e de uma vez por todas foi cerceado da prática de relações sexuais (direta) com sua esposa, afetando esta não só de maneira indireta, mas também direta, pois a mesma também não manterá mais relação sexual com o marido.

d) O parágrafo único do artigo 953, dispõe: "Se o ofendido não puder provar prejuízo material, caberá ao juiz fixar, equitativamente, o valor da indenização, na conformidade das circunstâncias do caso".

Revista IBERC, Minas Gerais, v. 2, n. 2, p. 01-22, mai.-ago./2019 


\section{Revista IBERC}

v. 2, n. 2, p. 01-22, mai.-ago./2019

www.responsabilidadecivil.org

O dano existencial está implícito no parágrafo único do artigo 953, cite-se como exemplo os danos sofridos pelos antigos donos da Escola Base, acusados injustamente de terem cometido crime de pedofilia e de aliciar os alunos da escola primária do qual eram proprietário, foram expostos à mídia e à sociedade, por circunstâncias jamais existentes. Tiveram a Escola Fechada e apedrejada, suas casas invadidas e seus projetos de vida interrompidos, não possuem mais o mesmo relacionamento social de antes, porque até hoje há quem acredite nas informações negativas e irresponsáveis divulgadas.

e) $\mathrm{O}$ artigo Art. 954 do Código Civil: que traz implicitamente a previsão do dano ao projeto de vida, representada na ofensa à liberdade pessoal, conforme será discorrido no tópico a seguir.

\section{UM DOS MAIORES CASOS DE DANO EXISTENCIAL OCORRIDO NO BRASIL EM QUE NÃO HOUVE A APLICAÇÃO CORRETA DE SUA TERMINOLOGIA}

O Sr. Marcos Mariano teve sua liberdade individual tolhida por uma prisão indevida, irregular e ilícita. O preso (vítima) permaneceu por 19 anos preso, sem que sequer the fosse dado o direito ao devido processo legal; ou que existissem provas que apontassem como acusado; ou muito menos que comprovassem ser ele penalmente responsável pelo crime de homicídio. O Sr. Marcos Mariano, sem que houvesse cometido qualquer delito foi preso irregularmente e ilicitamente, no lugar do real autor do ilícito. Durante o cumprimento da pena ele contraiu tuberculose e após seus olhos terem sido atingidos por estilhaços de bala de borracha, durante uma rebelião na penitenciária ele ficou bilateralmente cego.

Não foi apenas a integridade psicofísica da vítima que foi irreparavelmente lesada, mas de toda a sua família, porque ambos foram privados de suas convivências recíprocas. Como reparar o que não se pode mais restituir, como o tempo que já passou?

A indenização do dano existencial é calculada sobre os prejuízos às atividades de realizações do lesado, que implique consequentes alterações de conteúdo apreciável monetariamente. Seja sob o ponto de vista pessoal ou relacional, portanto, com consequências externas na vida daquele que sofreu o dano existencial.

Para demonstrar o efetivo prejuízo sofrido, a vítima pode utilizar como prova das presunções dos "fatos notórios" ou das noções de "experiência comum"; ou mesmo das situações reais baseadas na realidade sintomática em que o lesado se encontra. Em todos os casos, deve haver a verossimilhança ou elevado grau de probabilidade daquilo que se alega ter sofrido. Para o arbitramento da indenização, por exemplo, dever-se-á ter em conta fatores como a personalidade do sujeito lesado, o interesse violado, a atividade desenvolvida pela vítima, as repercussões do 


\section{Revista IBERC}

v. 2, n. 2, p. 01-22, mai.-ago./2019

www.responsabilidadecivil.org

dano sobre a personalidade do sujeito lesado e as alterações provocadas pelo dano, no âmbito familiar social da vítima.

\section{CONCLUSÃO}

Em tempos recentes, a doutrina e a jurisprudência comparadas, a codificação latinoamericana e em particular a legislação italiana, passaram do conceito genérico do dano à pessoa, à reparação dos prejuízos causados aos direitos sociais.

As relações internas (da pessoa consigo mesma) e as relações externas (da pessoa com o mundo em que vive e com as demais pessoas com quem se convive), deveriam ocorrer de modo pacífico e harmonioso. A coexistência deve ser garantida pelas normas existentes no tempo e no espaço em que as pessoas convivem em sociedade. As normas jurídicas devem servir à prevenção a eventuais danos causados à pessoa e à repressão das lesões provocadas indevidamente, a fim de que se promova a justiça, a paz e o bem comum.

$\mathrm{O}$ fato do dano existencial atingir valores fundamentais da vida humana (integridade física, saúde, paz, alegria, reputação e a própria vida, entre outros), diversos dos direitos da personalidade, faz evidenciar sua autenticidade, o seu caráter inovador e o seu ineditismo.

Os aspectos jurídicos do dano existencial estão correlacionadas com o direito à vida de relações e com os conceitos do ser-no-mundo, ser-com-os-outros.

O dano existencial se irradia, ele é externo, de um lado ele fere um interesse individual, mas de outro lado ele ocasiona uma alteração em todas as demais pessoas que estão em uma vida de relações com a vítima. A sociedade como um todo é prejudicada, pois as relações interpessoais são afetadas e modificadas, o objetivo de proteger a pessoa humana contra os danos deve voltar-se também para quem sofre indiretamente com as consequências do dano existencial.

O reconhecimento do dano existencial cumpre, pois, uma relevante função social, pois, além de ampliar as modalidades de danos já existentes, é um dano não patrimonial diverso do dano moral, podendo-se cumular as duas espécies de dano, e protege a vítima de um dano causado a em suas relações pessoais, sociais, profissionais, afetivas, etc. Possibilitando àquele que sofreu o dano em ricochete ser indenizado, na exata proporção da lesão que the fora causada. Repercutindo interesses individuais e coletivos em relação à sua aplicabilidade concreta, promovendo uma maior consciência quanto à obrigatoriedade das regras de responsabilização civil a que todos indivíduos estão submetidos.

O dano existencial é representado pela lesão ao prazer da pessoa, ao levar em consideração que a motivação é uma consequência do prazer de viver e a razão primordial do 


\section{Revista IBERC}

v. 2, n. 2, p. 01-22, mai.-ago./2019

www.responsabilidadecivil.org

existir das pessoas. Sem motivação, o indivíduo perde o sentido da sua existência e da busca de realizações e conquistas pessoais. $\mathrm{O}$ dano existencial pode provocar à vítima a perda da simples qualidade de apreciar as coisas e pessoas que estão ao seu redor. A existência fomenta a ação humana e esta é a razão de ser e de existir do Direito.

\section{REFERÊNCIAS}

BELTRÃO, Sílvio Romero. Direitos da personalidade. De acordo com o novo Código Civil. São Paulo: Atlas, 2005.

BETIOLI, Antônio Bento. Introdução ao Direito. São Paulo: Saraiva, 2013.

BILBAOS UBILLOS, Juan María. Direito Civil Contemporâneo. Gustavo Tepedino (org). São Paulo: Atlas, 2008.

CHRISTANDL, Gregor. I/ diritto privato oggi. La risarcibilità del danno esistenziale. Milano: Giuffrè Editore, 2007.

CICCO, Maria Cristina De. A pessoa e o Mercado. In: O direito civil contemporâneo. Novo problema à Luz da Legalidade Constitucional. Anais do Congresso Internacional de Direito Civil Constitucional da Cidade do Rio de Janeiro. São Paulo: Atlas, 2008.

FACHIN, Luiz Edson. A Construção do Direito Privado Contemporâneo na experiência CríticoDoutrinária brasileira a partir do Catálogo Mínimo para o Direito Civil- Constitucional no Brasil. In. TEPEDINO, Gustavo (org). Direito Civil Contemporâneo. São Paulo: Atlas, 2008.

JONAS, Hans. O princípio responsabilidade. Ensaio de uma ética para a civilização tecnológica. Rio de Janeiro: Contraponto Editora PUC Rio, 2006.

LÔBO, Paulo. Constitucionalização do Direito Civil. Revista Informação Legislativa. Brasília, Senado Federal, v. 36, n. 141, p. 99-109, jan/março, 1999.

LÔBO, Paulo. Tradição patrimonialista do Direito Civil e as tendências da repersonalização in Direito Civil. Parte Geral. São Paulo: Saraiva, 2015.

MIRAGEM, Bruno. Direito Civil. Responsabilidade Civil. São Paulo: Saraiva, 2015.

MORAES, Maria Celina Bodin de. Perspectiva a partir do Direito Civil-Constitucional. In O direito civil contemporâneo. Novo problema à Luz da Legalidade Constitucional. Anais do Congresso Internacional de Direito Civil - Constitucional da Cidade do Rio de Janeiro. São Paulo: Atlas, 2008.

MORAES, Maria Celina Bodin de. Danos à pessoa uma Leitura Civil-Constitucional dos Danos Morais. $4^{a}$ tiragem. São Paulo: Renovar, 2009.

PEREIRA, Caio Mário da Silva. Responsabilidade Civil. Atualizador Gustavo Tepedino. São Paulo: Saraiva, 2016. 


\section{Revista IBERC}

v. 2, n. 2, p. 01-22, mai.-ago./2019

www.responsabilidadecivil.org

PERLINGIERI, Pietro. A doutrina do Direito Civil na Legalidade Constitucional in O direito civil contemporâneo. Novo problema à Luz da Legalidade Constitucional. Tradução de Carolina Tomasi e Jõao Bosco Medeiros. Anais do Congresso Internacional de Direito Civil - Constitucional da Cidade do Rio de Janeiro. São Paulo: Atlas, 2008.

PONTEL, Evandro. Considerações sobre a Política em Jean-Jacques Rousseau e Alain Badiou. Disponível em: http://ebooks.pucrs.br/edipucrs/anais/semanadefilosofia/XI/32.pdf. Acesso em: 12/04/2018. Publicação em 19.08. 2007.

RODOTÀ, Stefano. La revoluzione della dignità. Napoli: La Scuola de Pitagora Editrice, 2013.

SARTRE, Jean Paul. O existencialismo é um humanismo. Rio de Janeiro: Vozes, 2010.

SESSAREGO, Carlos Fernández. El daño al proyecto de vida. In: GÓMEZ, José N. Duque. Del daño, compilación y extractos. Bogotá: Editora Jurídica de Colombia, 2001.

SessaRego, Carlos Fernández. Protección Juridica de la Persona. Lima: Publicaciones de la Universidad de Lima. 1. ed., 1992.

TEPEDINO, Gustavo. O Direito Civil-Constitucional e suas perspectivas atuais. In. O direito civil contemporâneo. Novo problema à Luz da Legalidade Constitucional. Anais do Congresso Internacional de Direito Civil - Constitucional da Cidade do Rio de Janeiro. São Paulo: Atlas, 2008.

Recebido: 10.01.2019

Aprovado: 05.02.2019

Como citar: BUARQUE, Elaine. O dano existencial como uma nova modalidade de dano não patrimonial: a necessidade da ampliação do princípio da função social da responsabilidade civil e a busca da reparação integral do dano à pessoa. Revista IBERC, Minas Gerais, v. 2, n. 2, p. 1-22, mai.-ago./2019 